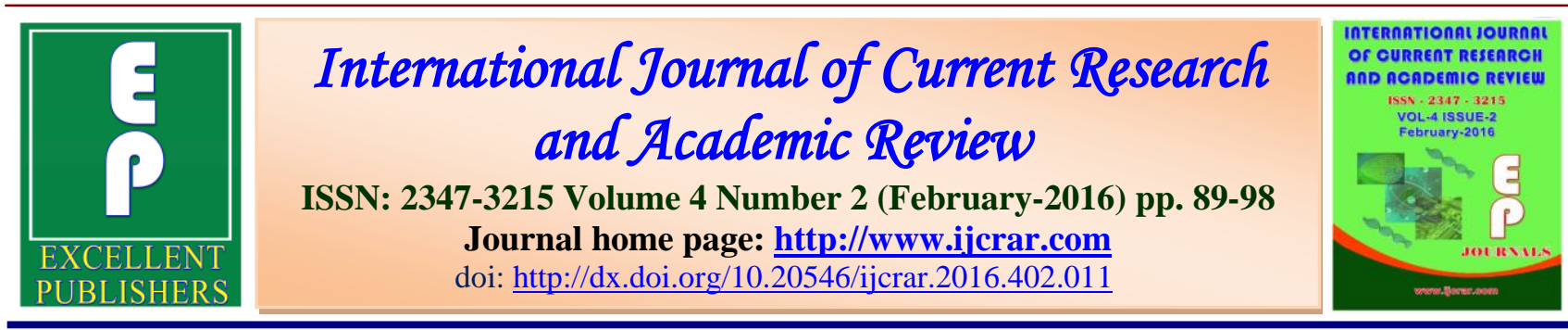

\title{
Synthesis, Biological Evaluation and invitro stability of New Schiff Bases of cytarabine Mutual Prodrugs
}

\section{Mohsin O.Mohammed*}

Department of Chemistry, College of Science, Kirkuk University, Kirkuk, Iraq

\section{*Corresponding author}

\begin{tabular}{|l|l|}
\hline \multirow{2}{*}{$\begin{array}{l}\text { KEYWWORDS } \\
\text { Leukaemia }\end{array}$} & A B S T R A C T \\
Suchiff base & $\begin{array}{l}\text { Cytarabine (Ara-C) is a chemotherapeutic agent predominately used for the } \\
\text { treatment of acute myeloid leukemia and lymphoblastic leukemia. In this } \\
\text { work, a new method of synthesis seven Ara-C Schiff base derivatives and } \\
\text { study their effect on inhibiting the growth on certain pathogenic bacteria were } \\
\text { described. Almost all analysed compounds inhibit the health of the studied } \\
\text { bacteria significantly. Synthesised compounds were subjected to a stability } \\
\text { study in phosphate buffer }(0.2 \mathrm{M}, \mathrm{pH} 7.4) \text { and in } \mathrm{KCl} / \mathrm{HCl} \text { buffer }(0.2 \mathrm{M}, \mathrm{pH} \\
\text { 1.2) at different time intervals }\left(0-240 \text { min) incubated at } 37^{\circ} \mathrm{C} \text {. This revealed }\right. \\
\text { that all synthesised compounds are significantly stable and have longer } \mathrm{t} \\
\text { comparison in } \\
\text { prodrug had a much less toxicity and may be considered for further biological } \\
\text { screening and application trial. }\end{array}$
\end{tabular}

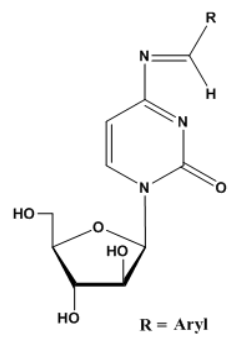

\section{Introduction}

Cytarabine (cytosine arabinoside, $1-\beta$-Darabinofuranosyl-cytosine, Ara-C) figure 1, a pyrimidine nucleoside analog, is mainly used against acute myelogenous leukemia and non-Hodgkin's lymphoma. It also has antiviral and Immune-suppressant properties (Jabbour E.et al., 2007; Shah, M., and Agarwal B., 2008).Ara-C used in combination with other anticancer drugs for the treatment of leukemia and solid tumors 
(Pinilla-Ibarz J., and Bello C., 2008; Matsumura I., 2009).Ara-C as nucleoside analogues is inactive by itself and requires phosphorylation to the corresponding triphosphate (Ara-CTP) in vivo to exert its antineoplastic activity by inhibition of nucleic acid biosynthesis and is rapidly delaminated by cytidine deaminase (CDA). Ara-C is a polar nucleoside and has a short plasma half-life. Although Ara-C is stable in the solid state, it's degraded by hydrolysis in aqueous solutions. A study on the re-formed stability of Ara-C in intravenous admixtures with sodium bicarbonate in plastic syringes were carried out by Munson et al. due to the increased use of high-dose from Ara-C in the treatment of neoplasms, the results of this study show that sodium bicarbonate 50 $\mathrm{mEq} / \mathrm{l}$ in the intravenous solution containing Ara- $\mathrm{C}$ has no effect on the chemical stability of Ara-C for at least 1 week at room temperature or in the refrigerator (MunsonJ. W.et al., 1982).Hydrolytic deamination of Ara-C results in the elimination of ammonia and the formation of uracil arabinoside(Notari, R. E. et al.,1970).The Ara-C, like all nucleoside analogues (such as gemcitabine, 5-fluorouracil, and fludarabine), suffers from several limitations. It has a low permeability in intestinal membrane and is rapidly deaminated to biologically inactive $1-\beta-\mathrm{D}$ arabino-furanosyluracil in the intestinal and hepatic cells leading to a very low oral bioavailability. Thus, continuous intravenous infusion of higher doses is required to maintain constant a plasma level of the drug in 8-24 h. The higher doses of Ara-C lead to toxicity to normal organs and side effects (Capizzi R. L et al.,1991). Consequently, many prodrug strategies have been explored to avoid the deamination and also to enhance the cellular uptake of Ara-C, but few have led to an approved product (Greenwald, R. B.et al., 2003).Recently there has been an emphasis on the development of Ara-C derivatives to obtain compounds with a higher therapeutic index for the treatment of leukemia and lymphoma. Among the explored alternatives, the prodrug strategy by introducing modifications on the parent drug to enhance plasma half-life or delivery to cancer cells is a subject of major interest. This design approaches included designing amino acid- Ara-C (Jin, M.et al., 2008; Sun, Y.et al., 2009), amino acid-fatty acid- AraC (Liu, B. et al., 2009), Ara-C phosphate derivatives(Peterson L. W. and McKenna C. E., 2009), and 5'-O-unsaturated fatty acid derivatives (BergmanA.M.et al., 2004). Schiff bases derivatives showed a wide range biological activity as an antimalarial, antibacterial, antifungal, and antiviral(Da Silva C. M. et al., 2011). As part of a study to prepare Ara-C-Schiff base and delineate their specific biological properties, we now report an attempt to produce new Schiff base derivatives of Ara-C that may have broader spectrum of activities, acid stable and could be used in the treatment. A new series was designed and synthesized, as new Schiff bases of Ara-C.To assess the feasibility of the prodrug for injection administration, haemolytic activity test was carried out.

\section{Materials and Methods}

\section{Synthesis of $\quad \boldsymbol{\beta}$-bromo-D-arabino- furanoside}

D-(-)-arabinose was treated with $\mathrm{HCl}$, freshly prepared by addition of acetyl chloride to anhydrous methanol at $0^{\circ} \mathrm{C}$, working up with pyridine rather than ammonium carbonate (Mikhailopulo I. A. and Sivets G. G., 1999), to give methyl- $\alpha, \beta$ D-arabinofuranoside (Araf) 1 (Scheme 1), with predominant formation of the $\alpha$-anomer $(\alpha / \beta, 3: 2)$ (Sanki A. K. et al., 2008; Cuzzupe A. N., 2002).In order to isolate the anomers, esterification of 1 under standard conditions to give tribenzoate 2 and 3 was first carried 
out. The $\alpha$-anomer 2 was separated from the $\beta$-anomer 3 by precipitating it in ethanol. Purification by column chromatography afforded the $\beta$-anomer 4 in $50 \%$ yield (Scheme 1) (Ramamurty C. V. S. et al., 2011). The methoxy group in compound 4 was converted into a bromide with hydrogen bromide (30-32\% in acetic acid) to give 5 as a white foam in $90 \%$ yield, which was used without further purification (Schneider R. F. et al., 1997) (Scheme 1).

\section{Synthesis of Cytosine-Schiff Bases}

The formation of imines (Schiff base) between Cytosine $\mathbf{6}$ and different aldehydes was carried out by using a combination and modification of the methods of Kundu et al. (Kundu A. et al., 2009) and Khrushcheva et al. (Krrushcheva N. S. et al., 1997) Seven derivatives of Cytosine (compounds 7a-i) were designed and synthesized as new Schiff bases derivatives (Scheme 2).The structures of these compounds were confirmed by NMR $\left({ }^{1} \mathrm{H}\right.$ and $\left.{ }^{13} \mathrm{C}\right)$, Mass spectroscopy IR spectrometry (see supplementary data).

\section{Synthesis of Ara-C-Schiff Bases}

The synthetic approach to synthesize the Schiff base derivatives of Ara-C is depicted in scheme 3. Schiff base of cytosine (7a-i) was reacted with compound 5 under basic conditionto give the corresponding compounds (8a-i) followed by removal of the benzyl protecting groups using sodium methoxide in methanol giving the desired compounds (9a-i) scheme 3. Once again, the structures of these compounds were confirmed by NMR $\left({ }^{1} \mathrm{H}\right.$ and $\left.{ }^{13} \mathrm{C}\right)$ and Mass spectroscopy (see supplementary data).

\section{Results and Discussion}

A series of Cytosine Schiff base derivatives was synthesized using three approaches. Firstly the glycan part compound $\mathbf{5}$ was obtained from D-(-)-arabinose as prepared in our last study (Scheme 1) (Mohammed M. O. et al., 2015). The second approach was formation of Cytosine Schiff base derivatives which based on reaction of cytosine with different aromatic aldehydes (Scheme 2). This method was carried out by using a combination and modification of the methods which have been already described (Kundu A. et al., 2009; Krrushcheva N. S. et al., 1997). The reaction of cytosine with 'aromatic' aldehydes was found to proceed smoothly and quantitatively in anhydrous conditions and heated in a microwave oven (7a-i) (Scheme 2). The final approach was formation of the Schiff base derivatives of Ara-C (Scheme 3). Cytosine Schiff base derivatives $(7 \mathrm{a}-\mathrm{i})$ then reacted with $\beta$ bromo-D-Araf5 under basic condition to give the corresponding compounds followed by removal of the benzyl protecting groups using sodium methoxide in methanol giving the desired compounds (9a-i) (Scheme 3).

\section{Experimental Section}

\section{Synthesis of Cytosine-Schiff Base}

General procedure:100 mg of cytosine base was put into a $1.7 \mathrm{~mL}$ microfuge tube, with an equal weight of the aldehyde and anhydrous sodium sulphate. The mixture was suspended in $500 \mu \mathrm{L}$ xylene and heated in a microwave oven (Daewoo model KOR6135) three times, for $3 \mathrm{~min}$ each time, at maximum power. The reactions were then left at $90^{\circ} \mathrm{C}$ for $24 \mathrm{~h}$. Imine synthesis requires anhydrous conditions and is known to proceed also in solid phase reactions. Xylene was used to facilitate the heat transfer processes in the reaction mixture and the reaction ingredients are insoluble to it. Sodium sulphate was included to help remove traces of water present in the reactants or generated during the Schiff base formation. At the end of the reaction period, the mixtures had the appearance of a white 
paste, with most of the xylene and water having evaporated.

\section{Synthesis of Ara-C-Schiff Base}

General procedure:To a suspension of Schiff base of cytosine (7a-i, $1.72 \mathrm{mmol})$ in dry THF $(20 \mathrm{~mL}), \mathrm{NaH}(60 \%$ dispersion in mineral oil, $3.44 \mathrm{mmol}$ ) was added and stirred at r.t. for $2 \mathrm{~h}$. A solution of the glycan $(5,2.23 \mathrm{mmol})$ in dry $\mathrm{THF}(5 \mathrm{~mL})$ was added to the mixture in one portion and the reaction mixture was stirred for $24 \mathrm{~h}$ under nitrogen atmosphere. The reaction was monitored by TLC. Solvent was evaporated under vacuum and the residue was dissolved in dichloromethane $(30 \mathrm{~mL})$, was washed with saturated aqueous sodium $\mathrm{Na}_{2} \mathrm{CO}_{3}$, brine and dried over anhydrous $\mathrm{Na}_{2} \mathrm{SO}_{4}$. The solution was filtered, concentrated, and the residue was subjected to purification by flash chromatography with $\mathrm{CH}_{2} \mathrm{Cl}_{2} / \mathrm{CH}_{3} \mathrm{OH}$ $(20: 1, \mathrm{v} / \mathrm{v})$ as eluent to give the desired compound (8a-i). To a cold solution of the benzoyl ester $(0.82 \mathrm{mmol})$ in dry $\mathrm{CH}_{2} \mathrm{Cl}_{2}(5$ $\mathrm{mL}), \mathrm{NaOMe}$ solution $(0.2 \mathrm{M}$ in $\mathrm{MeOH})$ (1.96 mmol) was added dropwise over 15 min. The reaction mixture was stirred at r.t. for $1 \mathrm{~h}$. An aqueous solution of $5 \% \mathrm{NH}_{4} \mathrm{Cl}$ was added to the mixture till the $\mathrm{pH}$ was 8 and the mixture was extracted with ethyl acetate $(3 \times 30 \mathrm{~mL})$. The combined organics were washed with brine, dried over anhydrous $\mathrm{Na}_{2} \mathrm{SO}_{4}$ and concentrated under reduced pressure to afford red oil residue. The residue was subjected to flash chromatography using hexane/ $\mathrm{CH}_{2} \mathrm{Cl}_{2}$ $(70: 30, \mathrm{v} / \mathrm{v})$ as the eluent to yield the final compound (9a-i).

\section{Antimicrobial Activity Assessment}

The in vitro antimicrobial activity of the synthesized compounds was tested against several pathogenic representatives: Bacillus subtilis, Staphylococcus aureus, Staphylococcus epidermidis, Klebsiella pneumoniae, Sarcinalutea, Pseudomonas putida and Clostridium perfringens. All microorganisms used were obtained from the culture collection of the Department of biology, college of science, Kirkuk University, Iraq. The antimicrobial screening, which is the first stage of antimicrobial drug discovery, was performed by the disc diffusion method Disc (Akter, T. et al., 2015). Media for disc sensitivity tests were nutrient agar and Muller-Hinton agar (MHA), purchased from Aldrich, (UK). The nonsterile powder of the tested compounds was dissolved in sterile DMSO to yield $2 \mu \mathrm{g} \mathrm{mL}-1$ passed through $0.2 \mu \mathrm{m}$ membrane filter (Millipore Corp., USA). The filtrates were dispensed as $2 \mathrm{~mL}$ samples into sterile, small screw-capped vials and kept stored at $-15{ }^{\circ} \mathrm{C}$. DMSO as a solvent showed no inhibition zones. The results were compared to cytarabine as a reference drug. The results are shown on Table (1). The antimicrobial screening showed that the newly papered compounds (9f and 9i) revealed reasonable antibacterial activities against all the strain used in comparison with Ara-C, which has no activity against this type of microorganism. Compound 9e showed good activity against all 6 strains of bacteria used, as compared with Ara-C while it was not sensitive against $P$. putida. Generally, all the remaining Schiff bases of Ara-C (compounds 9a, 9b, $9 \mathrm{c}$ and $9 \mathrm{~d}$ ) showed good and reasonable antimicrobial activity against the tested microorganisms. This increase in activity may be due to the incorporation of extra imine groups.

\section{Stability of the Synthesised Compounds in Aqueous Buffer Solutions}

Ara-C is not effective by mouth due to rapid deamination in the gastrointestinal tract; less than $20 \%$ of an oral dose is absorbed. After intravenous injection it disappears rapidly from the plasma with an initial half-life of 
about $10 \mathrm{~min}$; the terminal elimination halflife ranges from 1 to $3 \mathrm{~h}$ (S. Sweetman E., 2002).In order to study the half-life of the synthesized compounds, UV spectra of the aqueous solutions of the sodium salts of the new derivatives of Ara-C and the origin were carried out and their $\lambda_{\max }$ were recorded. The results are shown on Table (2).

According to the experimental conditions reported (Conover W., 1998), hydrolysis of synthesized compounds follow pseudo-first order kinetic, since plot of log concentration vs. time resulted in a straight line and from the slope of this plot, the observed rate constant of hydrolysis was calculated. The degree of hydrolysis of the papered compounds were studied at different time intervals $(0,15,30,60,120$ and $240 \mathrm{~min})$; solution of $(20 \mu \mathrm{g} / \mathrm{ml})$ from each compound was taken in $\mathrm{KCl} / \mathrm{HCl}$ buffer $(0.2 \mathrm{M}, \mathrm{pH} 1.2)$ and in phosphate buffer (0.2M, $\mathrm{pH} 7.4)$ incubated at $37^{\circ} \mathrm{C}$. The half-life values were calculated from the pseudo-first order kinetic law. Table 2 shows the results.

Accordingly, the above studies have indicated significant increase in the values of $t_{1 / 2}$ ofsynthesised compounds in comparison with Ara-Catboth acidic and slightly basic mediapH 1.2 and $\mathrm{pH}$ 7.4respectively (Paradis D. et al., 1992).

Table.1 Antimicrobial Activity Evaluation of the Synthesized Compounds ${ }^{\text {a }}$

Compound $t_{1 / 2}$ at pH $1.2 \quad t_{1 / 2}$ at pH $7.4 \quad \lambda_{\max } \mathrm{nm}$

\begin{tabular}{cccc}
\hline 9a & 3.48 & 15.25 & 460 \\
\hline 9b & 4.26 & 15.64 & 530 \\
\hline 9c & 5.74 & 16.75 & 470 \\
\hline 9d & 4.65 & 18.63 & 477 \\
\hline 9e & 5.25 & 16.85 & 489 \\
\hline 9f & 4.34 & 18.24 & 480 \\
\hline 9i & 4.15 & 16.57 & 507
\end{tabular}

Table.2 Half-Life Values and $\Lambda \max (\mathrm{Nm})$ of Synthesized Compounds

Compound / Disc diffusion test (mm)

\begin{tabular}{|c|c|c|c|c|c|c|c|c|}
\hline & Ara-C & $9 \mathbf{a}$ & $9 \mathrm{~b}$ & $9 c$ & 9d & $9 \mathrm{e}$ & 9f & $9 \mathbf{i}$ \\
\hline B. subtilis & - & + & + & + & + & + & ++ & ++ \\
\hline C. perfringens & - & + & + & + & ++ & ++ & ++ & ++ \\
\hline K. pneumoniae & - & + & ++ & + & + & + & + & +++ \\
\hline P. putida & - & ++ & ++ & + & + & + & ++ & ++ \\
\hline S. aureus & - & + & + & + & + & ++ & ++ & +++ \\
\hline S. epidermidis & - & + & + & ++ & ++ & + & + & ++ \\
\hline S. lutea & - & ++ & ++ & ++ & + & + & + & ++ \\
\hline
\end{tabular}


Int.J.Curr.Res.Aca.Rev.2016; 4(2): 89-98

Table.3 Hemolytic Activity of Synthesized Compounds

\begin{tabular}{c|c} 
Compound & $\begin{array}{c}\text { Hemolytic activity } \\
\mathbf{\%} \mathbf{\pm} \text { S.D }\end{array}$ \\
\hline Ara-C & 2.97 \\
\hline $\mathbf{9 a}$ & 21.20 \\
\hline $\mathbf{9 b}$ & 2.10 \\
\hline $\mathbf{9 c}$ & 10.72 \\
\hline $\mathbf{9 d}$ & 15.81 \\
\hline $\mathbf{9 e}$ & 13.65 \\
\hline $\mathbf{9 f}$ & 1.92 \\
\hline $\mathbf{9 i}$ & 1.8 \\
\hline $\begin{array}{c}\text { negative } \\
\text { control }\end{array}$ & 0 \\
\hline $\begin{array}{c}\text { positive } \\
\text { control }\end{array}$ & 100
\end{tabular}

Figure.1 Thestructure of Ara-C

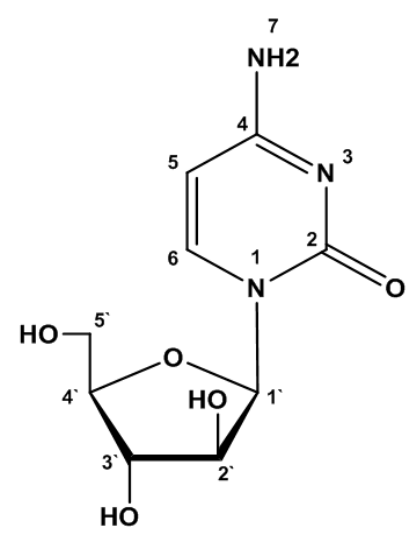

Figure.2 Hemolytic Activity of Synthesised Ara-C-Shiff Bases

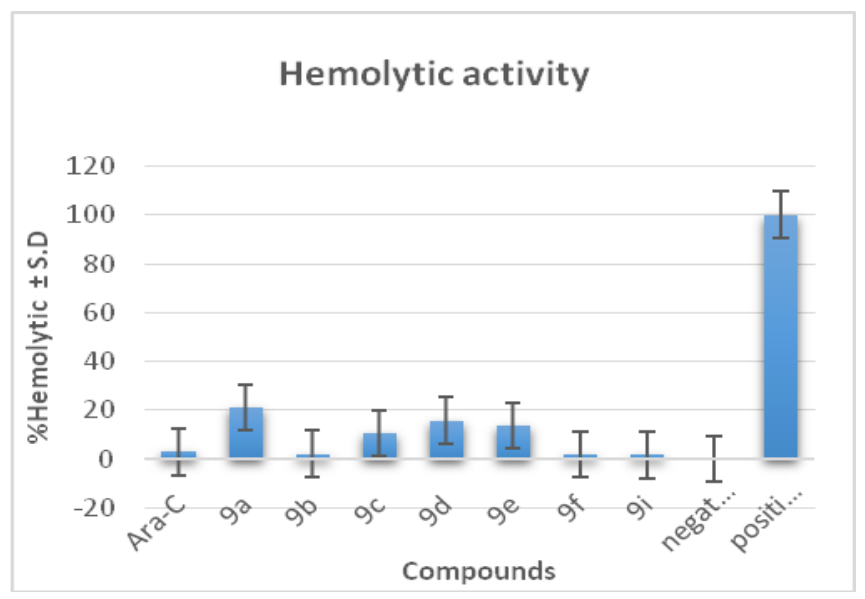


Int.J.Curr.Res.Aca.Rev.2016; 4(2): 89-98

Scheme.1 Reagents and Conditions: (I) Hcl, Ch3oh; (Ii) Bzcl, Pyridine, $0{ }^{\circ} \mathrm{C} / \mathrm{Rt}$, then $40{ }^{\circ} \mathrm{C} 1.5$ H, 50\% From B-Anomer (Iii) Hbr, Acoh, $90 \%$
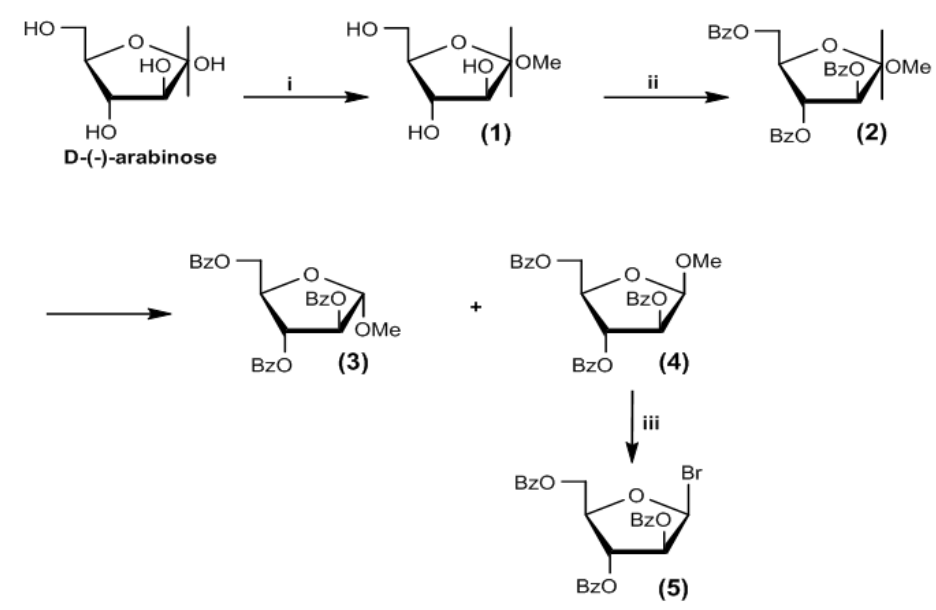

Scheme.2 Synthesis of Thecytosine -Schiff Base
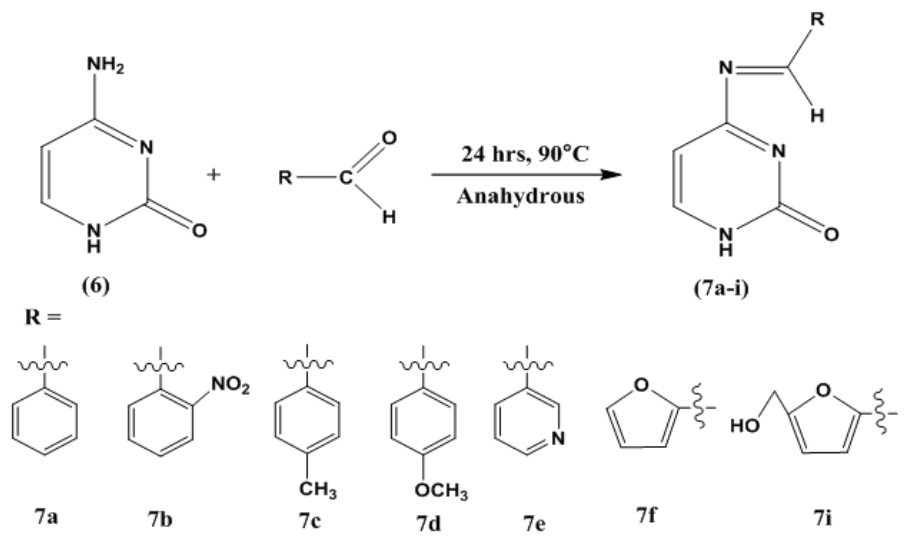

Scheme.3 Synthesis of the Cytosine -Schiff Base
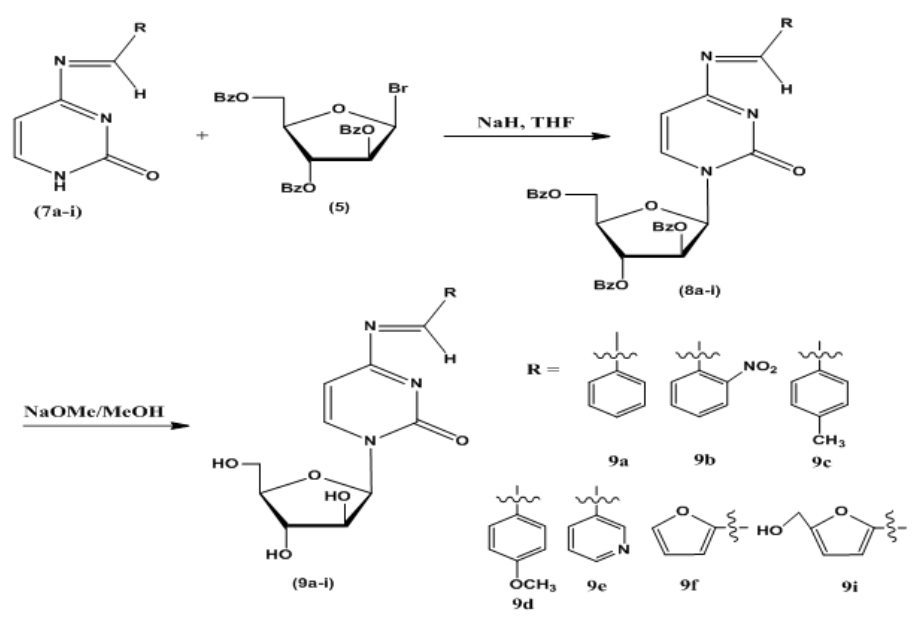


\section{Hemolytic Activity}

The RBC suspension was acquired as the reported method for hemolytic studies (Gul S. et al., 2014). Blood obtained from white rabbits was centrifuged at $4000 \mathrm{rpm}$ for 15 min and re-suspended in normal saline solution $(0.9 \% \mathrm{NaCl}$ solution) to obtain the red blood cells suspension (RBCs 2\%). RBCs $2.0 \mathrm{~mL}$ dispersed in $8.0 \mathrm{~mL}$ normal saline solution as a negative control (making no hemolysis) and RBCs $2.0 \mathrm{~mL}$ dispersed in a in $8.0 \mathrm{~mL}$ distilled water as a positive control (making 100\% hemolysis).Solution of $1 \mathrm{~mL}$ from each synthesised compounds, 2 $\mathrm{mL}$ RBCs suspension and $1 \mathrm{~mL}$ normal saline were incubated at $37.0 \pm 1.0{ }^{\circ} \mathrm{C}$ for 2 $\mathrm{h}$, followed by centrifuge the result solution at $4000 \mathrm{rpm}$ for $15 \mathrm{~min}$. The supernatant was isolated and measured spectrophotometrically at $541 \mathrm{~nm}$ which is the typical absorbance of haemoglobin $(\mathrm{Hb})$ released from RBCs, using normal saline as blank. The degree of hemolysis was determined for each sample using the following equation.

$\%$ Hemolysis $=\mathrm{A}$ sample-A negative controlA positive control-A negative control $\times 100 \%$

Where Asamples is the ultraviolet absorption of each compound at $541 \mathrm{~nm}$. A negative control and A positive control raises to negative control and positive control at $541 \mathrm{~nm}$, respectively. Table 3 and Figure 2, shows the result of hemolytic activity for synthesized compounds. Compounds 9i, 9f and $9 \mathrm{~b}$ rendered as the least cytotoxic because of the lowest hemolytic activity as 1.8\%, $1.92 \%$ and $2.10 \%$, respectively relative to positive control with that of $100 \%$. The lowest hemolytic activity for these compounds increase the potential of being used in pharmacies for drug development programs.

\section{Acknowledgment}

MOM wishes to thank the Ministry of Higher Education and Scientific ResearchKurdistan Region, Iraq for the award of the grant and I acknowledge the department of biology, college of science, Kirkuk University, Iraq for their help to carrying out the biological test.

\section{Supplementary Material}

Supplementary data includes synthetic procedures and the ${ }^{1} \mathrm{H}$ and ${ }^{13} \mathrm{C}$ NMR and IR, data for all tested compoundsassociatedwith this article can be found, in the online version, at

\section{References}

Akter, T., Mostafizur, K., \& Siddique, R. (2015). Antibiotic susceptibility investigations of fruits of parmentiera carefree seem by a standardized single disc diffusion methods. World Journal of Pharmacy and Pharmaceutical Science, 4(07), 2043-2047.

Bergman, A. M., Kuiper, C. M., Voorn, D. A., Comijn, E. M., Myhren, F., Sandvold, M. L.,Peters, G. J. (2004). Antiproliferative activity and mechanism of action of fatty acid derivatives

of arabinofuranosylcytosine in leukemia and solid tumor cell lines. Biochemical Pharmacology, 67(3), 503-11.

Capizzi, R. L., White, J. C., Powell, B. L., \&Perrino, F. (1991). Effect of dose on the pharmacokinetic and pharmacodynamic effects of cytarabine. Seminars in Hematology, 28(3 Suppl 4), 54-69.

Conover, W. (1998). Buffer Solutions: The Basics (Beynon, R. J.; Easterby, J. S.). Journal of Chemical Education, 75(2), 153. 
Cuzzupe, A. N., Di Florio, R., \&Rizzacasa, M. A. (2002). Enantiospecific Synthesis of the Phospholipase A 2 Inhibitor (-)-Cinatrin B. The Journal of Organic Chemistry, 67(13), 43924398.

Da Silva, C. M., da Silva, D. L., Modolo, L. V., Alves, R. B., de Resende, M. A., Martins, C. V. B., \& de Fátima, Â. (2011). Schiff bases: A short review of their antimicrobial activities. Journal of Advanced Research, 2(1), 1-8.

Gul, S., Abbasi, M. A., Khan, K. M., Nafeesa, K., Siddiqa, A., Akhtar, M. N., Subhani, Z. (2014). Synthesis, antimicrobial evaluation and hemolytic activity of 2-[[5-alkyl/aralkyl substituted-1,3,4-oxadiazol-2-yl]thio]$\mathrm{N}$-[4-(4-morpholinyl)phenyl] acetamide derivatives. Journal of Saudi Chemical Society.

Greenwald, R. B., Choe, Y. H., McGuire, J., \& Conover, C. D. (2003). Effective drug delivery by PEGylated drug conjugates. Advanced Drug Delivery Reviews, 55(2), 217-250.

Jabbour, E., Cortes, J. E., Giles, F. J., O'Brien, S., \&Kantarjian, H. M. (2007). Current and emerging treatment options in chronic myeloid leukemia. Cancer, 109(11), 2171-81.

Jin, M., Hong, J., \& Han, H. (2008). Synthesis and In-vitro Evaluation of N4-Amino Acid Derivatives of Cytarabine for Improving the Oral Delivery of Cytarabine. J. Kor. Pharm.Sci., 38(4), 255-259.

Krrushcheva, N. S., Loim, N. M., \&Sokolov, V. I. (1997). Solid-state synthesis of Schiff bases. Russian Chemical Bulletin, 46(11), 1952-1955.

Kundu, A., Shakil, N. A., Saxena, D. B., Kumar, J., \&Walia, S. (2009). Microwave assisted solvent-free synthesis and biological activities of novel imines (Schiff bases). Journal of
Environmental Science and Health. Part. B, Pesticides, Food Contaminants, and Agricultural Wastes, 44(5), 428-34.

Liu, B., Cui, C., Duan, W., Zhao, M., Peng, S., Wang, L., Cui, G. (2009). Synthesis and evaluation of anti-tumor activities of N4 fatty acyl amino acid derivatives of 1-beta-arabinofuranosylcytosine. European Journal of Medicinal Chemistry, 44(9), 3596-600.

Matsumura, I. (2009). Standard therapies for acute myeloid leukemia. [Rinshōketsueki] The Japanese journal of clinical hematology, 50(10), 1389400.

Mikhailopulo, I. A., \&Sivets, G. G. (1999). A Novel Route for the Synthesis of Deoxy Fluoro Sugars and Nucleosides. Helvetica ChimicaActa, 82(11), 20522065.

Mohammed, M. O., Baird, M. S., \& Al Dulayymi, J. R. (2015). Mycolyl arabino glycerols from synthetic mycolic acids. Tetrahedron Letters, 56(23), 3268-3272.

Munson, J. W., Kubiak, E. J., \&Cohon, M. S. (1982). Cytosine arabinoside stability in intravenous admixtures with sodium bicarbonate and in plastic syringes. Drug Intelligence \& Clinical Pharmacy, 16(10), 765-7.

Paradis, D., Vallee, F., Allard, S., Bisson, C., Daviau, N., Drapeau, C., LeBel, M. (1992). Comparative study of pharmacokinetics and serum bactericidal activities of cefpirome, ceftazidime, ceftriaxone, imipenem, and ciprofloxacin. Antimicrobial Agents and Chemotherapy, 36(10), 2085-2092.

Peterson, L. W., \& McKenna, C. E. (2009). Prodrug approaches to improving the oral absorption of antiviral nucleotide analogues. Drug Delivery, 6(4), 405420. 
Pinilla-Ibarz, J., \& Bello, C. (2008). Modern approaches to treating chronic myelogenous leukemia. Current Oncology Reports, 10(5), 365-371.

Ramamurty, C. V. S., Ganney, P., Rao, C. S., \& Fraser-Reid, B. (2011). Ready preparation of furanosyl npentenylorthoesters from corresponding methyl furanosides. The Journal of Organic Chemistry, 76(7), 2245-7.

Sanki, A. K., Boucau, J., Srivastava, P., Adams, S. S., Ronning, D. R., \&Sucheck, S. J. (2008). Synthesis of methyl 5-S-alkyl-5-thio-Darabinofuranosides and evaluation of their antimycobacterial activity. Bioorganic \& Medicinal Chemistry, 16(10), 5672-82.

Shah, M., \& Agarwal, B. (2008). Recent advances in management of acute myeloid leukemia (AML). Indian Journal of Pediatrics, 75(8), 831-7.

Sun, Y., Sun, J., Shi, S., Jing, Y., Yin, S., Chen, Y., He, Z. (2009). Synthesis,
Transport and Pharmacokinetics of 5'Amino Acid Ester Prodrugs of 1- $\beta$ - d Arabinofuranosylcytosine. Molecular Pharmaceutics, 6(1), 315-325.

Schneider, R. F., Engelhardt, E. L., Stobbe, C. C., Fenning, M. C., \& Chapman, J. D. (1997). The synthesis and radiolabelling of novel markers of tissue hypoxia of the iodinated azomycin nucleoside class. Journal of Labelled Compounds and Radiopharmaceuticals, 39(7), 541557.

S. Sweetman, E. (2002). Martindale: The Complete Drug Reference, 33rd ed. (33rd ed.). Pharmaceutical Press.

Notari, R. E., Chin, M. L., \&Cardoni, A. (1970). Intermolecular and intramolecular catalysis in deamination of cytosine nucleosides. Journal of Pharmaceutical Sciences, 59(1), 2832.

\section{How to cite this article:}

Mohsin O.Mohammed. 2016. Synthesis, Biological Evaluation and invitro stability of New Schiff Bases of cytarabine Mutual Prodrugs. Int.J.Curr.Res.Aca.Rev. 4(2): 89-98.

doi: http://dx.doi.org/10.20546/ijcrar.2016.402.011 